Curriculum-making in school and college: The case of hospitality

Richard Edwards, Kate Miller and Mark Priestley

The Stirling Institute of Education

University of Stirling

Stirling FK9 4LA

Email: r.g.edwards@stir.ac.uk 
Curriculum-making in school and college: The case of hospitality

\begin{abstract}
Drawing upon research in the curriculum of Hospitality, this article explores the contrasting ways in which the prescribed curriculum is translated into the enacted curriculum is school and college contexts. It identifies organisational culture and teacher and student backgrounds and dispositions as central to the emerging contrasts. It uses this evidence to argue that the evolution of credit frameworks which assume a rational curriculum is unhelpful in understanding the multiple plays of difference in learning and the enacted curriculum
\end{abstract}

Keywords: Curriculum-making, prescribed curriculum, described curriculum, hospitality, organisational culture, teacher dispositions, student dispositions 


\section{Curriculum-making in school and college: The case of hospitality}

\section{Introduction}

Over the years, there have been significant changes in the boundaries between secondary schooling and further education in the UK, but also a continued recognition of the challenges of transition from one institutional context to the next. With the attempts to expand opportunities for students by articulating different parts of the education and training system through the development of credit frameworks, such as the Scottish Credit and Qualifications Framework, and a common prescribed curriculum, questions arise over the nature and extent of similarities and differences in the enacted curriculum in different contexts. Here we take the prescribed curriculum as that inscribed in unit descriptors and outcome statements and the enacted curriculum to refer to the choreographing of people and artefacts in the enactment of practices - cognitive, practical, communicative - designated as learning.

At one level, the specifications of learning outcomes at particular levels within a common framework points to a rational curriculum within which attainment and progression is, in principle, transparent. Learning at the same level is assumed to be equivalent. However, while this may be the case in relation to the prescribed curriculum, what interests us in this article are the differences and similarities that emerge through the translation of the prescribed curriculum into different contexts, into what is enacted as learning. Taking a particular curriculum area, the study of Hospitality, we report on a research project that has sought to explore the curriculummaking practices in school and college in the context of Scotland to identify 
similarities and differences, but also the factors which are at play in the translations of the rational prescribed curriculum into practice.

The article is in four sections. First we outline the background to the project, the questions addressed and the methods adopted. Second we provide two case studies of curriculum-making in Hospitality, one from a school and one from a college. Hospitality in one of three curriculum areas we explored within the context of this project, the other's being Life Sciences and Technical Studies. These areas were chosen in consultation with the school and college that participated in this project, as 'telling cases', where similar or related curriculum at the same level were provided across the two settings. Third, we outline the factors from the data that most influence the translations from the prescribed to enacted curriculum. Finally, we draw out some inferences for curriculum policy and pedagogy from our analysis.

\section{Background to the project}

Historically, in Scotland, schools focussed on an academic curriculum, while colleges provided a more occupation-related curriculum (Bryce \& Humes, 1999; Leech, 1999). This has changed, as some schools have sought to provide more occupationally-oriented opportunities for students for whom the academic curriculum may be less appropriate, while colleges have developed their provision of the higher level occupation-related curriculum and also developed academic opportunities for students (Thomson, 2003; Canning, 2007). The result is that currently parts of the curriculum are common to both schools and colleges, both organisations provide learning opportunities for the 14-18 age range and there are increasing numbers of students attending both school and college at the same time. These changes impact 
upon curriculum coherence, transition and progression for students within the curriculum and between institutional contexts.

A number of curriculum initiatives, such as Curriculum for Excellence, have developed out of a desire for greater flexibility of curriculum offering and the extension of educational opportunities. In Scotland, this has been supported by developments, such as the Scottish Qualifications Authority (SQA) and the Scottish Credit and Qualifications Framework (SCQF). The SQA acts as a single awarding body for qualifications other than university awards. It therefore provides a single framework for both schools and colleges. While schools and colleges can offer programmes of study other than those provided under the auspices of the SQA, in practice this is not common. The SCQF, although still in an early stage of development, seeks to provide equivalence between different forms of learning and awards, to provide the possibility for credit accumulation and transfer between institutions and qualifications. The SQA sets its awards within the SCQF structure of levels and credits. To a greater or lesser extent, colleges and schools both offer courses at levels 2-7.

It is SQA unit descriptors which schools and colleges mainly utilise when developing a curriculum in particular subjects. These provide the basis for the 'regulative discourse’ (Bernstein, 1996) or ‘prescribed curriculum’ (Bloomer, 1997). Units are chosen either on the basis of the outcomes to be achieved, or staff in schools and colleges develop a curriculum and select the units required. In theory, there are many curriculum routes to achieve the outcomes, which provides the possibility for creative approaches to pedagogy on the part of institutions, departments and teachers/lecturers 
(Osborn et al., 1997; Higham, 2003). It is such possibilities that are often represented in the 'described curriculum' (Bloomer, 1997), those narratives of practice provided by teachers and lecturers.

However, evidence from around the world suggests that there is less diversity in the described and enacted curriculum than envisioned or desired (e.g. Cohen 1988; Smyth et al., 1998). Indeed many unit descriptors do not only specify outcomes, but also make broad statements about expectations in relation to teaching, learning and assessment practices to achieve those goals. There can thus be less scope for creativity arising from the prescribed curriculum than at first seems possible. At one level, this apparent standardisation might be said to be a good thing as it provides the basis for greater trust in the equivalence of learning within the qualifications frameworks. However, it might also be said to stifle diversity and creativity in the enacted curriculum.

To date research has mostly focused on the impact of the proliferation of centrally driven curriculum policy initiatives in recent years, described by Levin (1998) as an epidemic of policy. This points to a concern that there is more continuity than change in what goes on in schools and colleges (e.g. Cuban, 1988; Sarason, 1990; Helsby, 1999; Lang et al., 1999; Spillane, 1999; Goodson, 2004). Here continuity at one level ensures diversity, given the different organisational and subject cultures within the education system. Attempted change through the rational prescribed curriculum might be said to have been relatively ineffective. 
The reasons for this have been much researched over the years. For example, in relation to the school curriculum, Eisner (1992: 610) stated that 'it is much easier to change educational policy than to change the ways in which schools function'. Tyack and Cuban (1995: 88) talked of the difficulties in changing the grammar of schooling, those 'institutional habits and widespread cultural beliefs about what constitutes a "real school"'. Cuban (1984) identified a number of stability factors that militate against change in practice: e.g. schools prize obedience over independent thinking; the pragmatics of organisational structures; the existing culture of teaching; those who avoid risk are rewarded; and the socialisation of teachers through their own schooling.

Such factors contribute to the gap between the prescribed, described and the enacted curriculum and 'instructional discourse' (Bernstein, 1996). These latter might show some modifications, but change has been assimilated into the existing subject and organisational culture. Many of the reforms in curriculum since the 1980s have been characterised as a top-down, centre-periphery model of dissemination, described by Goodson (2003; xiii) as 'brutal restructuring' delivered in 'ignorance or defiance of teachers' beliefs and missions'. They can be viewed as an attempt to enforce an ever more prescribed curriculum, which according to one's perspective, is either to encourage greater innovation or reconfigure teachers as technicians (Ball, 2001).

The research suggests that attempts to provide a rational prescribed curriculum with equivalences across contexts is not being achieved in the enacted curriculum, which raises questions about the presumed equivalence of learning. To date, the research evidence overwhelmingly focuses on curriculum-making in schools. There is much less in the context of further education (James \& Biesta, 2007). Existing research 
identifies a range of factors which influence and militate against diversity in curriculum-making. This is significant insofar as curriculum reforms can be absorbed into existing organisational and professional cultures rather than being a vehicle to transform them (Cuban 1998). Thus, while in the prescribed curriculum there is a notional equivalence in terms of outcomes at a certain level of performance, in the enacted curriculum there can be a great deal of difference, which itself then raises questions about the equivalences established. In exploring the curriculum-making practices in similar units in Hospitality in school and college, we therefore raise questions about the assumptions of curriculum and learning in outcomes-based approaches to education and credit frameworks, as well as identify factors which result in differences in the enacted curriculum.

The factors affecting curriculum making can be identified at various levels, using a simple typology:

- contextual factors e.g. national policy, funding arrangements;

- organisational factors e.g. nature and size of institution and subject department, styles of management, level and type of resources, locus of decision-making, internal or external assessments;

- curriculum factors e.g. the ways in which the curriculum is prescribed, nature of the curriculum i.e. academic or vocational;

- micro-political factors e.g. collegial, hierarchical or individualistic, expectations of students and parents; and

- individual factors e.g. professional formation and dispositions of lecturers and teachers, student backgrounds and prior experiences. 
Thus, for instance, the availability of published textbooks and other resources, and teachers' existing frames of reference act to enable and constrain curriculum-making. Bates (1989) stresses the importance of teachers' material, especially career interests in determining how new initiatives are mediated. Doyle and Ponder (1977) suggest that teachers have a 'practicality ethic' which means new practices emerge when they are congruent with existing values, instrumental and the benefits outweigh the costs. Daniels (2001) refers to 'stuck' and 'moving' schools to contrast those in which teachers are less willing to take risks and those where this is not the case. One factor affecting this is a contrast between a hierarchical and collaborative culture. These factors could also be relevant in curriculum-making in the further education context also.

\section{Hospitality case studies}

In this section we draw upon the data to construct two short descriptive case studies of the curriculum making in Hospitality. These are based upon documentary analysis, and cycles of classroom observations and interviews with staff and students on the selected units over the course of one terms. All names are annonymised. These cases are illuminative rather than exhaustive. Two units were selected for comparison, each an Intermediate 2 (SCQF level 5).

The college Hospitality unit - Cookery Processes - had as its prescribed outcomes:

Describe the cookery processes, their associated principles, and foods suitable for each process. 
Perform numerical tasks related to food preparation.

Using commercial catering equipment, carry out the cookery processes to given specifications.

Interpret oral instructions and standard recipes to carry out the cookery processes on a range of foods.

The school Hospitality unit - Practical Skills for the Hospitality Industry - had as its prescribed outcome:

Prepare a range of food using appropriate techniques and equipment

Cook and present a range of food to an appropriate standard

Work in a safe and hygienic manner.

Both units therefore focus on enabling students to prepare food in a safe and hygienic way using appropriate equipment and techniques. Both units are part of courses with very similar overall aims. The college course - Professional Cookery - aims to provide 'a thorough introduction to the techniques, skills and knowledge required to operate in the kitchen areas of a wide variety of commercial establishments'. The school course Practical Cookery - aims to provide 'the development of techniques and skills required for food production appropriate to domestic and hospitality situations'. The difference between the two courses is in the inclusion of domestic situations in the course chosen by the school, whereas the college course is specifically aimed solely at a variety of commercial kitchens. The SQA provide these two courses with a slightly different emphasis and balance between the aims and learning outcomes. The institutions can then chose which course at this level is most appropriate to their own organisational aims and best suited to their staff and student profiles. 
Thus while one unit has an overall focus on professional cookery and the other on practical skills for the hospitality industry, both focus on learning to work in kitchens to prepare food. The similarity in the two units is emphasised by a certain commonality in the more detailed expectations of teaching, learning and assessment activities associated with the two units. However, when we explored the enacted curriculum there were significant differences in terms of context, the teacher and student body and the scale of activity expected of students.

\section{Hospitality - cookery processes}

This unit was taught by M, an ex-professional chef with many years experience of different kitchens, who gained his occupational qualifications part-time. His move into full-time lecturing at college was gradual and importantly influenced by personal reasons, in particular the desire for more family friendly working hours. Prior to becoming a lecturer, $\mathrm{M}$ had worked in Edinburgh, Glasgow, Aberdeen, Stirling and in Holland. He moved into tutoring while working in a restaurant, initially one day per week. He then obtained a one year temporary contract as a lecturer. His enthusiasm for restaurant work was broad based, not least the multiculturalism of the workplace 'people from different walks and different cultures'. While working, he was given the opportunity to gain teaching qualifications in the late 1990s. His approach to teaching could therefore be said to model forms of workplace apprenticeship.

The unit was taught over 2 lots of 18 weeks, with three kitchen-based sessions and one classroom-based session per week. Attendance by students can be erratic - M identified 1 or 2 of the nine students as 'not good attendees'. The unit was taught 
within the college in three adjacent rooms - a large kitchen, a small kitchen and a more conventional classroom. A lot of the work in the kitchens involves preparing food for the college restaurant which is open to the public. M starts by focusing on building up the students basic skills. When they get to a certain level they then start prepping the food for the restaurant. Later in the year they move on to preparing and cooking the menus for the restaurant. When working in the kitchens, the students and staff all wear professional clothing - white, coats, hats, cheffing trousers. This wear is provided to students at the start of their course, along with knives and a Cookery Book that has all the information they need to pass the assessment for the Unit. Successful completion of the course enables them to keep these items. The kitchens are laid out as one would find professional kitchens. This, alongside the clothes and equipment, indicate the attempt to foster an atmosphere similar to that to be found in actual workplaces in the hospitality industry, reflecting the historic role colleges have played in relation to occupationally-oriented education. The equipment and activity mean there is a lot of noise, heat and movement in the kitchens.

However, there are also some small trappings of the conventional classroom within the kitchens with flipchart and text books. The flipchart displays the menu they are working on and the numbers of portions needed. The text books are open and the students follow instructions on food preparation from them. There is also a folder with the recipes for the restaurant menus. The students move between using the recipes for large numbers of customers from the folder and the precise instructions around processes for smaller numbers found in the text book. In the kitchens the students seem comfortable with what they are being asked to do and very focused on the task in hand. 
The classroom is laid out with student tables forming a rectangle, with the lecturer at the front. There is a digital screen and audio-visual equipment for teaching purposes. An Over Head Projector sits on the lecturer's desk. As well as class-related items on their desks, the students often have mobile phones, drinks and ipods visible, giving a certain informality to the atmosphere. This contrasts with the formality of their uniforms in the kitchens which need to be clutter free of personal items for health and safety reasons. This change in activity and use of space is also signalled through a more informal chatty style which punctuates the more focused instructional discourse of the classroom interactions. In the kitchen the whole focus is on the food preparation and any chat between teacher and students tends to be about or related to the task in hand.

M sought an integrated approach to his teaching, embedding core skills into the subject curriculum and not over-emphasising assessment. There is no clear distinction between some of the units which are taught in an integrated way in the kitchens. His approach could be termed practice-led, as he was keen to support the development of the working practices necessary for the occupation with which he had strong and ongoing links. The knowledge of theoretical aspects of the unit he tried to draw from the students' practical experience, although this tended to take place after the event in the classroom-based part of the course. He also emphasised the social aspects of becoming a chef, in needing to develop the networks within the profession. Outside speakers from the hospitality industry were therefore brought in to talk with students and M encouraged his students to have part-time jobs in hospitality while studying. 
The occupational relevance of the curriculum and the fostering of occupational dispositions did not preclude $\mathrm{M}$ from being relatively personable at times with students. He introduced comments and observations about himself and his personal life and views at points in his teaching. However, it was also notable that when M left the kitchen the students became more chatty. His role as lecturer therefore entailed an authoritative presence. In general though, the atmosphere was relatively relaxed.

In the large kitchen, a lot of the teaching was a combination of doing by the students and demonstrating by $\mathrm{M}$. In the early sessions, this was a staged process within the session. As the unit progressed, so $\mathrm{M}$ spent less time demonstrating. When not demonstrating, he walked around the kitchen, observing and commenting on students’ work. He was also assessing, but this seemed to be a relatively unobtrusive activity, as not all the students were aware it was taking place. $\mathrm{M}$ described himself as assessing through observing and giving the students feedback, but this did not seem to reflect what was enacted. $\mathrm{M}$ also timed assessment to take place later in the unit, once students had had time to practice the tasks against which they were to be assessed.

In the early sessions, while the students were producing their own individual food, they worked in pairs, talking with each other, providing peer support. At the end of cooking, the students cleaned the kitchens and this was drawn upon in discussing issues around health and safety in the classroom-based sessions.

A later session in the large kitchen was very buzzy, with much more of the feel of a commercial kitchen. The students were doing preparation for Christmas dinners in the restaurant and a second lecturer was working with $\mathrm{M}$. Both were involved in 
demonstrating food preparation and asking short questions for students to answer. The students used their text books to guide them and there was less demonstrating than previously. Students were reminded about health and safety issues as they engaged in tasks. The importance of team work in a kitchen was also emphasised. The students were encouraged to use the full range of their senses in food preparation - smell, taste, look, etc. - and reminded that aspects of cooking are to do with personal preference in terms of taste. $\mathrm{M}$ went around giving advice, instructions and encouragement. He recognised the greater intensity - 'it's to give the guys a little bit of a push'. This was based on the increased scale of cooking for large numbers compared to the smaller number of portions prepared at the start of the unit.

Classroom-based sessions were positioned as ‘theory' and, for the students, were the least favoured part of the course - 'it's the theory work that's kind of difficult I find... I'm not really managing it very well' (B). M explained that the students were to watch a video, which was followed by questions to elicit answers for the revision sheet. $\mathrm{M}$ gave plenty of affirmation of correct answers, but also reframed them into the technical language necessary for assessment. He was very positive and reassuring. If someone's attention strayed, he directed a question to them.

In addition to the video, the students drew upon the pack of materials supplied at the start of the unit. The pack contained activity sheets, information and a log book. The latter was meant to be filled out after a kitchen sessions, but this was often done during the classroom sessions. $\mathrm{M}$ once again used tangential issues - e.g. the college change of name - to introduce wider issues, in this case on the history of Andrew Carnegie, and his role in philanthropy. He introduced citizenship issues into his class. 
The students in this group were diverse in terms of age and background. Most had some previous or current affiliation to cooking. A number identified themselves as having not enjoyed school and been disruptive, yet they seemed focussed and working hard in the sessions observed.

In a further session in the kitchen, there were initial interruptions as someone came to congratulate the students on the buffet they had prepared for a staff function and another person came to consult $\mathrm{M}$ about something. Pairs and groups were given particular tasks in food preparation. The menu was on a flipchart in the corner and the students seemed to know what they had to do. They had circulated around from one task to another over the course of the unit acquiring a diversity of experiences. The students used textbooks, photocopied restaurant recipes and $M$ as a resource. The main issue for the students was working out how the individual bit they were working on contributed to the whole menu. In this session, they were prepping a complex and challenging menu to be cooked for the Christmas dinner in the restaurant for external guests. One of the students (A) gave a sense of the busyness of the environment - 'its always keeping you on your feet anyway, it sure is me’.

\section{Practical cookery skills for the hospitality industry}

This unit was taught by P who was a teacher of Home Economics. She had started a degree in Food, Health and Welfare and, following a three week placement in a school, decided to become a teacher. She trained at Aberdeen University and then got a temporary post at the school in which she now teaches. Her practical experience of 
Hospitality was domestic rather than commercial. The teacher was immaculately dressed in fashionable clothes indicating a certain artistic flare.

The unit was taught in one room in the Home Economics department of the school. The department was on the second floor and the corridor was full of posters promoting healthy eating and the smell of food and cooking pervaded. The classroom was divided into many kitchenette areas with a sink, oven, cupboards to store equipment and a work surface. The doors of the cupboards had diagrams on them to show what should be stored there. There was a walk-in cupboard at the front of the class which held fridge freezers and large containers. The scale was more domestic than commercial, as were the number of portions of food the students produced. The kitchen combined as a classroom with a teacher's desk at the front with a digital board. There was a rotating white board also. The computer in the classroom was used by P to display the learning outcomes of that class, to access emails and the like, but also to search the internet for information.

The full title of the unit was only placed on the inside cover of the teacher's workbook. On all other school produced materials e.g. student workbook and support notes and the recipe booklet, the unit was simply called Practical Cookery. This, alongside the scale of cookery in the class, suggests the occupational relevance of the unit was somewhat diminished. As it was her first time of teaching the unit, $\mathrm{P}$ worked entirely from the school produced packs. It was noticeable that the students seemed very positive about the unit precisely because it was more practical than most of the curriculum they were studying and required less writing. However, there is a question 
of the extent to which that practicality was geared towards cookery per se and/or the cookery skills for the hospitality industry.

There were four students for this class, all female. Two were very interested in Home Economics, while the other two were doing the course more as a respite from their more academic studies. The small class contrasts with an equivalent class in the school, which had 18 students. The different size of groups arose from timetable issues within the school. For $\mathrm{P}$, the small group allowed for a more informal and interactive style of teaching. Students wore a white apron over their day clothes. The students paid for the ingredients they used on a monthly basis. They filled out their workbooks as they went along, listing recipes and the like and they used it as a reference point if they were stuck when doing assessments.

One student, J, had actually done a four week day release courses at college the previous year. She contrasted the two environments - 'It was good but if you're in the kitchen for so long its like hard work because its really hot because its like big industrial cookers and things like that, and you burn yourself more easily. But it was good fun. It was good'. The physical demands of the curriculum in the different contexts marked a significant difference.

P placed the learning outcomes for each class on the digital board. She went over them with the class. The scale of the servings was small - four. Because of time constraints, not all aspects of the processes being engaged with were contained within the one class. As the students tried the techniques, $\mathrm{P}$ walked up and down, watching and giving instructions. She also asked questions to elicit the reasons students were 
using certain ingredients. P also demonstrated cookery techniques, such as cake making, which the students copied individually. P provided lots of encouraging comments to the students. At the end she instructed them to wash up their utensils and checks that ovens were turned off.

In a further session, the learning outcomes were once again displayed. P was enthusiastic about the use of technology - 'I use it every lesson, even if it's just used as a whiteboard, a projection board for putting the aims and objectives up for that lesson... It's just a different medium to use in the classroom as a resource'. P instructed the students to gather around her with tomatoes, knives and chopping board so she could demonstrate how to cut a serrated garnish. A student asked how to do a tomato rose as a garnish. As $\mathrm{P}$ was not sure, she searched on the web and found instructions on how to do this. In this lesson a student took over the control of the computer to scroll through a website with recipe instructions while the teacher performed the task described. At the end of this class, P informed the students what they would be cooking next and suggested they check the recipe. She also took a note of who had paid for ingredients.

In a third class, the equipment had been laid out in advance for the students. The two keen students entered first and moved straight into doing things. One wanted to make an appointment for her parents to meet $\mathrm{P}$ at the parents evening. The learning objectives were on the screen and the students had the recipe books out as a point of reference. The two less keen students arrived and were told by P to 'get prepped'. Once again, the students got on with things and $\mathrm{P}$ walked up and down being fairly informal and chatty, but keeping them on task, which the students seemed to like. She 
seemed to struggle with one of the students (K) who was particularly slow and appeared not much interested.

P reminded the students they had an assessment coming up and suggested they take home worksheets which were normally kept in the back of the classroom, in order to revise. K got in a muddle over separating eggs and the very keen students helped her with the process. The two keen students were always ahead of the two less keen. $\mathrm{P}$ tried to help K who had fallen further behind.

Pressure of time seemed a fairly constant factor. The students were making cakes. P instructed them to whisk the cream with an electric mixer once the cakes were in the oven. In principle, they should not use the electric whisk for this task but time was short. P had the students set timers for the cakes (which ended up burning), and the students washed up and put away equipment. There was an even greater sense of hurriedness to this session than previous ones.

The final observed class focused on decorating and presenting food rather than preparing it. The students prepared and got their cookbooks out. They had made the shortbread and puree the previous session. P demonstrated the combining of puree with cream to form the filling for the shortbread and explained how the property of icing sugar enables it to set. She instructed them to wipe down surfaces and choose a garnish. While the students were wiping down surfaces, $\mathrm{P}$ did a drawing on the whiteboard of her proposed display of food on the plate. She gave the students a range of ideas for displays but said it was their choice how they did it. 
She gathered the students around and demonstrated the decorating of the plate she had drawn. P involved the students in making the decisions about what would look good as she did this. The students did their own designs and P helped them to finish these. Once again $\mathrm{K}$ had a lot of problems in achieving the end result. P had the students show their finished displays to the Principal Teacher, who was also very positive about them. One student took a photo of the design on her mobile phone. P gave them permission to taste one of the deserts, after which they washed up.

\section{Factors influencing curriculum-making}

The case studies above illuminate the different practices that emerge in the enacted curriculum as it is translated into specific contexts. Thematic analysis of the data indicates two areas of greatest significance in helping to explain this: individual and organisational factors. This is not to deny other factors that influence translations. However, within the context of this article we want to focus on those that have emerged as most significant.

Individual factors influencing curriculum-making includes for example the professional formation and dispositions of lecturers and teachers, and student backgrounds and prior experiences. In relation to these, there is a distinct contrast between $\mathrm{P}$ and $\mathrm{M}$ and also the student groups they are teaching.

$\mathrm{P}$ went from school to university then back into school as a teacher. She had been teaching at the school for eight years, and this was her only school. Her mother was a headteacher of a primary school. 'I vowed I would never be a teacher... the thought of secondary scared the living daylights out of me' (P). However, after two weeks of a 
school placement while doing her undergraduate degree, she 'just got such a buzz out of it, such buzz'. Her lack of commercial experience and connections was reflected in a lack of awareness of how things are developed at SQA. P tended to follow the sessions as laid down in her materials, although with occasional deviations, such as the preparation of the tomato rose. The deviations from the prescribed curriculum tended to be of an artistic and creative nature which connects to her artistic inclinations. She could then be said to have a strong curriculum focus in her teaching, with the purpose of getting students through their assessment. Any wider curriculum purpose beyond subject coverage in the direction of the hospitality industry would appear to be limited.

P followed the learning outcomes as prescribed, although with creative flourishes. She was however critical of the types of meals that were specified as necessary for assessment. She felt the meal reflected individual dishes put together for the purpose of demonstrating assessment criteria rather than combinations of dishes that worked well together. She brought an enthusiasm about food and a professionalism based on taste and design to her teaching. She was very loyal to her colleagues and proud of their department and what they could offer to the students. She was also very concerned about how the decisions of the senior management team around funding and availability of a range of different units and qualifications would impact on some of the students progression routes into hospitality and care-related occupations.

By contrast, M’s experience as a chef and his contacts in the hospitality industry meant that he had a very clear sense that he was preparing students for the occupation. This curriculum purpose resulted in $\mathrm{M}$ introducing elements into his teaching that 
enhanced the prescribed curriculum specifically around preparing students for the industry. M had a clear view of the different aspects to hospitality that need to be learned - 'the food-side... the customer-side... the hygiene-side... the safety-side'. The practical focus to the curriculum was valued by the students. M tried to develop their understanding of the theory aspects of the course by drawing upon the practical, but this was not unproblematic. It was a 'curriculum for the industry' (M). He saw theory and practice as going hand-in-hand, although there seemed to be some tension between this and the differentiation between the kitchen and classroom sessions. $M$ recognised the importance of contacts in the industry for students to obtain work and encouraged this through inviting external contributions to the course and students to have part-time work in hospitality. He was clear about the orientation as a professional course aiming towards a 'professional cooking exam'. Interestingly, given the position of the hospitality teaching in the Home Economic department of the school, M explicitly differentiated ‘professional hospitality' from 'home economics'. M identified the staff in schools as not having the relevant experience to provide the professional focus. He contrasted himself as 'tutor' with a 'teacher'.

M's personal commitment to hospitality was evidenced by the way he promoted it to potential students - 'I really gonna sell hospitality', 'I have a passion about it'. He talked in enthusiastic terms of teaching - 'I still enjoy it. I love it'. He bought books about cookery and brought them into the college for students to use. He also recognised the intensity for students - 'they’re having to learn new things every second they come in'. 
$\mathrm{M}$ also saw himself as treating the students as adults, giving them more autonomy. In the class he liked to negotiate rules and expectations with students. However, the views from the students were more mixed. Most identified their engagement with $\mathrm{M}$ as different from school, but not always as clearly as $\mathrm{M}$ himself saw it. This points to the importance of the students as actors in the curriculum-making process.

The college students often had prior experiences of working in hospitality and a clear desire that this was their career direction. The role of other members of their families in working in hospitality also seemed significant in terms of the reproduction of occupational aspirations. For instance, W's father and sister both worked in hospitality. A number of students also aspired to join the armed forces and saw hospitality as an occupation to follow therein - 'I've come here to do catering here first for a year and then I'm going to do it on a boat... its good money and you're getting trained’ $(\mathrm{J})$. This raised interesting potential tensions between M’s understanding of hospitality in relation to commercial restaurants and the students' aspiration to learn catering for the armed services.

Some of the college students expressed themselves as having bad school experiences. This reflects a tradition in colleges of offering educational opportunities to students who do not do well in school. One student had left school at 15 and was home tutored. $\mathrm{N}$ identified himself as having been 'a bit load, obnoxious, to tell you the truth'. W referred to his exit from school in interesting terms - 'I just left, just got wiley ideas.... I just left and then decided [to come to college]'. Contrasting their experience of college with school was common. At school 'just loads of information chucked at you, and you're meant to learn it' $(\mathrm{N})$. N saw the teaching in college as 
more being treated like an adult - 'in a way its up whether you want to learn or not, rather than being told you have to learn it'. The culture of the class was less focused on discipline than school. Thus when going to the toilet, 'you just say you are going, you don't have to actually like ask' (B). Some students liked help from staff but not in the way it was provided in school. Other students like to try things out for themselves.

By contrast, the school students were very different in terms of background and aspirations. Like the students in college, some students had connections into the occupation, for example, $\mathrm{T}$ who had an uncle and cousin who were chefs. However, all these students aspired to go to university rather than into the workplace. C cooked for her boyfriend and was a keen student who wanted to study Hospitality at university to become a Home Economic teacher, much to the surprise of P. For other students in the group, studying cookery was seen as relatively easy by contrast with other more academic subjects. For instance, for K 'it's a bit different... it breaks up the day a bit, than sitting in the classroom'. $\mathrm{K}$ at first said she wanted to study Accountancy at university but later was considering going on the stage.

The background and aspirations of the students from the school and the college appear to match their teachers/lecturers backgrounds in at least some respects. AM had left school early having had a rather unsatisfactory experience at school. He went into the industry and learnt the trade from his professional practice and training. $\mathrm{P}$ stayed on at school and then went on to university to do an occupationally orientated degree before specialising in teaching. M’s focus in his teaching is on preparing the students for the industry and sharing his passion for food and his broader ethos on life. P's focus is on the food and the artistic aspects of food preparation and appreciation. 
She is equally passionate about her role as teacher in terms of getting the students to appreciate the importance of the artistic side of cooking, which can only be achieved through a thorough knowledge of the ingredients and processes involved. The students studying hospitality at school have not been rejected or rejected the school and still see that they can use the hospitality experience within the organisational environment of the school. The students at the college have all rejected or been rejected by the schools they attended and are looking for something different. The prescribed curriculum is really not very different on paper, but the college environment in terms of spaces, artefacts, rules and interactions are significantly different from their perspective.

The occupational orientation of the college enacted curriculum can be contrasted with that in the school, reflecting wider institutional culture as well as the differing backgrounds and aspirations of both staff and students. However, in one respect, there is also a great similarity for students. All students positively contrasted learning in the kitchen environment with more conventional classrooms - 'its good 'cause it doesn’t most of the time doesn't feel like you're learning anything because you're just, you're doing it', 'Listen to the teacher 'cause it can lose concentration with the... In the kitchen and stuff you can't really loose concentration'. So while their study of Hospitality did not always arise from direct interest in the subject, nor in moving into the occupation, the students at school, like those at college, valued its more practical nature. In other words, it was the participative form of learning that engaged them more than the acquiring of knowledge. The school students thus contrasted the Intermediate 2 they were studying with the more academic Standard grade - 'more like written. You don’t really cook much’ $(T)$. The practical nature of the course 
seemed to the students to provide more reinforcement of their learning - 'you remember if you ruin a cake, but one can forget what one has written'.

Organisational factors that influenced curriculum-making in these cases included the nature and size of the institution and subject departments, styles of management, level and type of resources, the organisation of space and time, and the locus of decisionmaking. The Hospitality department in the college had a large staff base with a variety of expertise across the industry to draw on. They also worked closely with staff in other subjects - e.g. Enterprise and Social Studies - to pool resources and provide cross-curricular projects. For example, the design and construction of a new restaurant was done in collaboration with the Construction students. They also have themed nights in the restaurant where the students invite the Drama and Language students to help with entertainment. Students advertise the evening in the local paper and with posters in the college. The proceeds are then used to invest in the department.

The Hospitality department in the school mainly consisted of part-time female staff with little or no direct experience of the industry. They did have other experience and expertise to draw on, but this contributed to a distinctly female and more domestic feel to the way the curriculum was enacted. There was a high degree of loyalty and cooperative working between the members of the department, but less cross-curricular working.

In the school, the timetabling had had an impact on size of class, which impacted upon the type and level of interactions between the teacher and students. The class size was originally eight but had dropped to four because of timetabling issues. $\mathrm{P}$ 
identified the individual attention she was able to give the students as advantageous, because 'their skills come on much, much quicker, much and much better... much more chilled out'. Double sessions were identified also as advantageous over single sessions in order to address the compression of activities by the timetable. There was only a limited possibility of obtaining these highly prized timetable slots.

Timetabling was also an important influence in the college. $\mathrm{M}$ contrasted the three hour sessions in college with the shorter sessions in schools. Working in a timely manner is important in professional cookery, and the sense of needing to work within the limits of the timetable was enhanced by the requirement to prepare food for the restaurant. The organisation of space was also significant. In contrast with the school's kitchen, which was set up like a number of domestic kitchens and students cooked on a domestic scale, in the college, the kitchens were similar to those to be experienced in the workplace. The suite of rooms with two kitchens and a classroom with good equipment supported the curriculum well and $\mathrm{M}$ used a wide range of medium. The fact the students were given professional clothes, knives and a cookery book suggests good resourcing of this area. The college students also received a bursary whereas the school students had to pay for their ingredients and provide containers and dishes. Staff-student ratios were good at roughly 9-1 (the limit is 14), but this was partly governed by Health and Safety legislation, given the way the kitchens were set up to run like their commercial equivalents.

\section{Inferences}

Although ostensibly taking similar units within a unified and rational curriculum framework, it is clear that the enacted curriculum in Hospitality varies significantly 
across the different contexts of school and college. A focus on individual and organisational factors helps us to understand how the translation from prescribed to enacted curriculum occurs. We may infer from this one case that schools and colleges may provide similar opportunities at a formal level, but they are very different organisations serving different student groups and with often different types of staff with varying professional formations. Curriculum-making is therefore very different in the different organisations. What implications can we infer from this?

If we take a rational view of curriculum, we might decry the differences in the enacted curriculum and seek ways to produce greater consistency. Further standardisation becomes necessary. This assumes difference can and should be eradicated. If we take a practice focused view of the curriculum, it then becomes important to realise the ways in which the enacted curriculum is differentiated in order to avoid false assumptions about achievement, articulation and progression. It also becomes necessary to recognise that achieving similar outcomes as specified in the prescribed curriculum does not mean that one has engaged in equivalent learning, despite what might be inferred from the development of credit frameworks. Acquiring similar outcomes can be based upon participation in very different learning experiences. In this sense, some of the discussion about turning teachers into technicians through prescribed outcomes-based curriculum seems somewhat misplaced, as organisational and individual factors already do support the play of difference in curriculum-making. More creativity may be desired in curriculum-making, but this would entail addressing the existing play of difference, which is not simply about curriculum policy. 
We can see from these two examples of how Hospitality curricula are enacted that the staff and students bring considerable creativity and initiatives from their own individual perspectives, which then shape and are shaped by the organisational contexts of which they from a part. Policy initiatives which intend to promote creativity, amongst other attributes, in terms of student and teacher engagement would do well to consider the plays of difference and creativity already employed by teachers and students within the constraints of a rationalised prescribed curriculum framework if they want to avoid the disdain of teachers. As one teacher remarked in relation to 'Curriculum for Excellence' initiative in the college.. 'It's like trying to teach your grandma to suck eggs’.

These are significant inferences. They arise from research in one curriculum area. The question then becomes one of the extent to which similar issues arise from the study of other curriculum areas, and how differentiated the enacted curriculum is across the full range of education and training providers. However, rational the prescribed curriculum and credit structures may be, difference remains infused in the enacted curriculum. Equivalence of learning is therefore a far more substantive issue than the prescribed rational curriculum suggests.

Note

This article is based on a research project, Curriculum-Making in School and College, funded by the ESRC (RES -000-22-2452). Our thanks to the staff and students that made this project possible.

\section{References}


Ball, S. J. (2001) '‘You’ve been NERFed!’ Dumbing down the academy: National Educational Research Forum: 'a national consultation paper': a brief and bilious response’. Journal of Education Policy 16(3): 265-268

Bates, I. 1989 'Versions of vocationalism: an analysis of some social and political influences on curriculum policy and practice'. British Journal of Sociology of Education 10(2): 215-231

Bernstein, B. (1996) Pedagogy, Symbolic Control and Identity. London: Taylor and Francis.

Bloomer, M. (1997) Curriculum making in post-16 education. London: Routledge.

Bryce, T. \& Humes, W. (1999) 'Scottish Secondary Education: Philosophy and Practice'. In Bryce, T.G.K \& Humes, W.M. (eds.), Scottish Education. Edinburgh: Edinburgh University Press

Canning, R. (2007) 'A History of Core Skills Development Policy in Scotland'. Scottish Educational Review 39(2): 138-147

Cohen, D.K. (1988) 'Teaching Practice: plus ca change...’. In Jackson, P.W. (ed.) Contributing to Educational Change: perspectives on policy and practice. Berkeley: McCutchan

Cuban, L. (1984) How teachers taught: constancy and change in American classrooms 1890-1980. New York: Teachers College Press

Cuban, L. (1988) 'Constancy and change in schools (1880s to the present)'. In Jackson, P.W. (ed.) Contributing to Educational Change: perspectives on policy and practice. Berkeley: McCutchan

Cuban, L. (1998) 'How schools change reforms: redefining reform success and failure’. Teachers College Record 99(3): 453-477

Daniels, H. 2001. Vygotsky and pedagogy. London: Routledge.

Doyle, W. \& Ponder, G.A. (1977) 'The Practicality Ethic in Teacher DecisionMaking'. Interchange 8(1): 1-12

Eisner, E.W. (1992) 'Educational Reform and the Ecology of Schooling'. Teachers College Record 93(4): 610-626

Goodson, I.F. (2003) Professional Knowledge, Professional Lives. Maidenhead: Open University Press

Goodson, I.F. (2004) 'Understanding Curriculum Change: some warnings about restructuring initiatives’. In Hérnandez, F. \& Goodson, I.F. (eds.). Social Geographies of Educational Change. London: Kluwer Academic Publishers

Helsby, G. (1999) Changing Teachers' Work. Buckingham: Open University Press 
Higham, J.J.S. (2003) 'Curriculum Change: a study of the implementation of general national vocational qualifications’. The Curriculum Journal 14(3): 317-340

James, D. \& Biesta, G.J.J. (2007) Improving learning cultures in Further Education. London: Routledge

Lang, M., Olson, J., Hansen, H. \& Bunder, W. (1999) 'Professional development and the challenge of curriculum reform’. In Lang, M., Olson, J., Hansen, H. \& Bunder, W. (eds.), Changing Schools/Changing Practices: perspectives on educational reform and teacher professionalism. Louvain: Garant

Leech, M. (1999) 'Further Education in Scotland Post-incorporation'. In Bryce, T.G.K \& Humes, W.M. (eds.), Scottish Education. Edinburgh: Edinburgh University Press

Levin B. (1998) 'An Epidemic of Education Policy: (what) can we learn from each other?’ Comparative Education 34(2): 131-141

Osborn, M., Croll, P., Broadfoot, P., Pollard, A., McNess, E. \& Triggs, P. (1997) 'Policy into practice and practice into policy: creative mediation in the primary classroom'. In Helsby, G. \& McCulloch, G. (eds.) Teachers and the National Curriculum. London: Cassell

Smyth, J., McInerney, P., Hattam, R. \& Lawson, M. (1998) 'Teacher learning: the way out of the school restructuring miasma', International Journal of Leadership in Education, 1/2, 95-109

Spillane, J. (1999) 'External reform efforts and teachers' initiatives to reconstruct their practice: the mediating role of teachers' zones of enactment'. Journal of Curriculum Studies, 31(2): 143-175

Thomson, C. (2003) 'Further Education in Scotland'. In Bryce, T.G.K \& Humes, W.M. (eds.), Scottish Education: second edition, post-devolution. Edinburgh: Edinburgh University Press

Tyack, D. \& Cuban, L. (1995) Tinkering toward utopia: a century of public school reform. Cambridge: Harvard University Press 